\title{
COMUNICACÕES
}

\section{Ocorrência de mela causada por Rhizoctonia solani AG4-HGI em plântulas de algodoeiro no Brasil}

\author{
Augusto César Pereira Goulart ${ }^{1}$, Joana Bernardes de Assis², Maisa Boff Ciampi ${ }^{3}$; Paulo Cezar Ceresini²,4
}

\begin{abstract}
${ }^{1}$ Embrapa Agropecuária Oeste - Caixa Postal 661, 79804-970, Dourados, MS; ${ }^{2}$ ETH Zurich, Institute of Integrative Biology (IBZ) - Plant Pathology, Universitaetstr. 2, LFW B28, 8092, Zurich, Switzerland; ${ }^{3}$ Universidade de São Paulo, Escola Superior de Agricultura Luiz de Queiroz, Departamento de Fitopatologia, 13418-900, Piracicaba, SP; ${ }^{4}$ UNESP - Universidade Estadual Paulista, Campus de Ilha Solteira, Departamento de Fitossanidade, Engenharia Rural e Solos, 15385-000 Ilha Solteira, SP

Autor para correspondência: Augusto César Pereira Goulart. (goulart@ cpao.embrapa.br)
\end{abstract}

Data de chegada: 19/11/2009. Aceito para publicação em: 25/01/2011.

O tombamento de plântulas de algodoeiro, causado por Rhizoctonia solani Kuhn grupo de anastomose AG4 (teleomorfo: Thanatephorus cucumeris (A.B. Frank) Donk), é uma doença que está amplamente disseminada no Brasil, principalmente nas regiões dos cerrados dos estados de Mato Grosso, Mato Grosso do Sul, Minas Gerais, Goiás e Bahia. Os danos associados ao tombamento são significativos já na fase inicial de estabelecimento do algodoeiro pela redução da população de plantas e, às vezes, pela necessidade de ressemeadura. A ocorrência dessa doença no país tem sido favorecida pela monocultura do algodoeiro associado ao preparo intensivo do solo (o qual facilita a dispersão do fungo), o que frequentemente favorece situações de alagamento e encharcamento contribuindo para o aumento do potencial de inóculo do patógeno na área. A utilização de sementes com baixo vigor associada ao plantio em épocas favoráveis à ocorrência desta enfermidade são também fatores predisponentes ao ataque de $R$. solani que devem ser considerados. A partir da safra 2004/2005, lavouras de algodoeiro no estado de Mato Grosso, vem apresentado alta incidência de uma forma peculiar da doença, distinta da forma clássica de tombamento. Ocorrendo sempre na fase inicial de desenvolvimento do algodoeiro (fase de plântula - cotiledonar) reduz significativamente o estande e, em casos mais sérios, tem levado à ressemeadura. Os sintomas iniciais caracterizamse por lesões nas bordas dos cotilédones, evoluindo para o encharcamento (anasarca), seguida de destruição total dos cotilédones e posterior morte da plântula. Esta doença está sendo denominada de "mela do algodoeiro" e é predominantemente foliar. Além do Mato Grosso, esta enfermidade foi detectada nos estados de Mato Grosso do Sul, Minas Gerais, Goiás e Bahia. Plântulas de algodoeiro com sintomas da doença foram levadas para a Embrapa Agropecuária Oeste, Dourados, MS, para identificação do agente causal. Para o isolamento do patógeno, fragmentos de tecidos lesionados foram submetidos inicialmente à "câmara-úmida", favorecendo o crescimento de estruturas do patógeno nestes tecidos e, posteriormente, transferidas para meio de cultura BDA (batatadextrose-ágar) e incubadas a $22^{\circ} \mathrm{C}$. Após sete dias foram observadas colônias de coloração castanha, com crescimento micelial abundante e presença de hifas grossas, multinucleadas e ramificadas em ângulos de $90^{\circ}$. Microescleródios formaram-
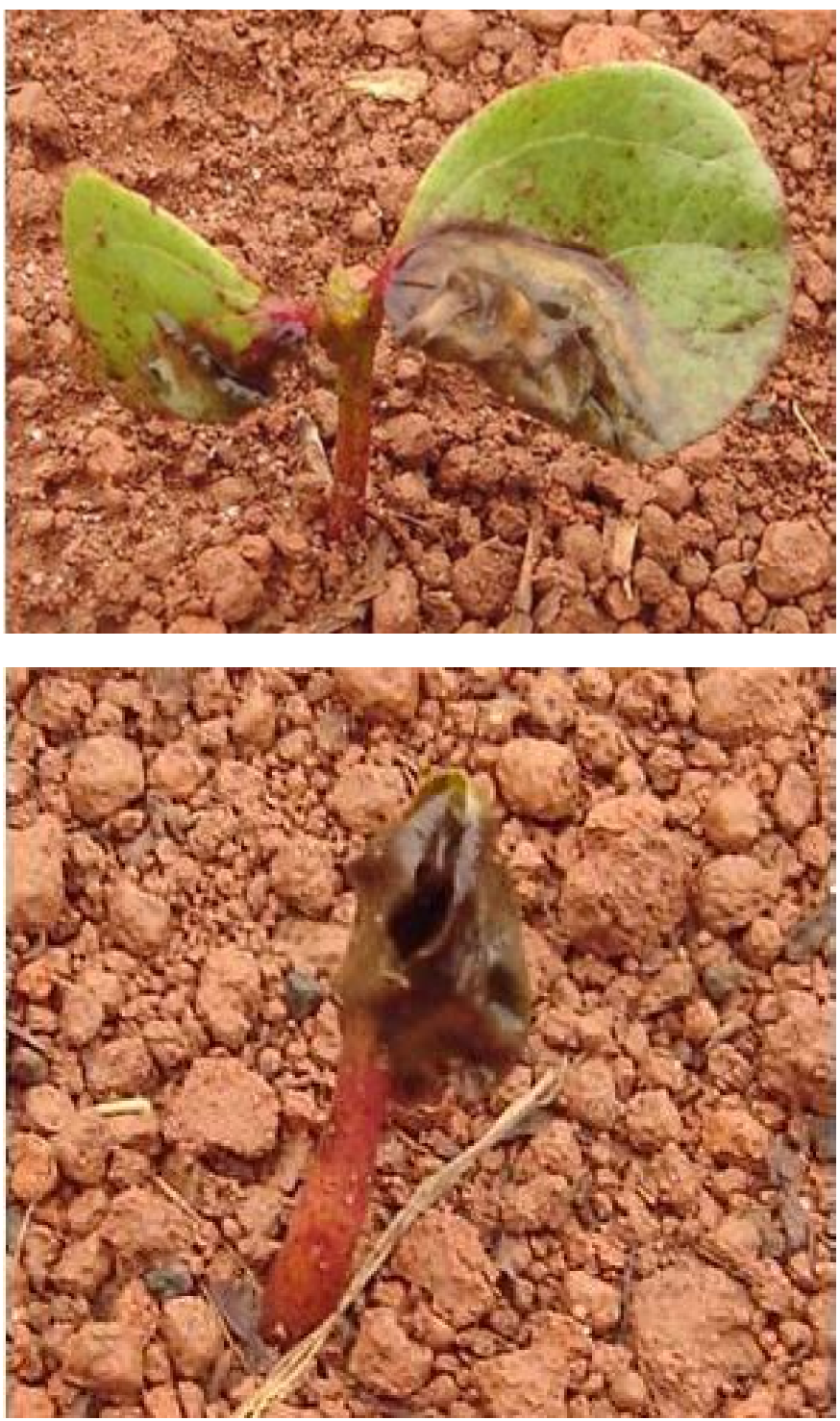

Figura 1. Plântulas de algodoeiro com sintomas de mela (R. solani AG4HGI) 
se após o $15^{\circ}$ dia de incubação. Com base nestas características morfológico-culturais, o fungo foi identificado como Rhizoctonia solani. O teste de patogenicidade foi conduzido em casa de vegetação, onde sementes de algodoeiro, cv. DeltaOpal, foram semeadas em vasos, contendo como substrato terra esterilizada (Latossolo Vermelho Distroférrico). A inoculação do substrato e de plântulas de algodoeiro recém emergidas foi realizada, através da pulverização de suspensão de fragmentos de micélio e escleródios. Os vasos foram mantidos em condições de elevada umidade tanto do ambiente como do solo, de modo a proporcionar condições semelhantes às ideais para a ocorrência da doença ( $U R=90 \%$ e temperatura em torno de $25^{\circ} \mathrm{C}$ ). Após sete dias da inoculação, sintomas da "mela" idênticos aos observados a campo foram também observados nas plântulas de algodoeiro inoculadas. O patógeno foi reisolado e identificado como $R$. solani, completando-se assim os postulados de Koch. Os isolados do patógeno tiveram o grupamento de anastomose determinado por sequenciamento da região ITS-5.8S rDNA no Eidgenössische Technische Hochschule Zürich (ETHZ), na Suíça. As seqüências da região ITS isoladas de $R$. solani da "mela do algodoeiro" foram semelhantes às do grupo de anastomose AG-4 HGI, até então não relatado no Brasil como patógeno foliar do algodoeiro. No Brasil, o AG-4 foi relatado como patógeno foliar apenas na cultura do feijoeiro (Bolkan, H.A. \& Ribeiro, W.R.C. Anastomosis groups and pathogenicity of Rhizoctonia solani isolates from Brazil. Plant Disease 69:599-601. 1985). Embora não tivéssemos detectado himênio e basidiósporos associados às lesões, é possível que basidiósporos (fase perfeita do patógeno) tenham importância como inóculo primário no ciclo da "mela do algodoeiro". Importante ressaltar que este fungo, $R$. solani AG4, já é patógeno na cultura do algodoeiro, causando a doença conhecida como "tombamento", caracterizada pela formação de lesões no colo e nas raízes das plântulas de algodão, sintomas bem distintos das lesões cotiledonares observadas no presente estudo. Este é o primeiro registro no Brasil da ocorrência de $R$. solani AG4-HGI em plântulas de algodoeiro.
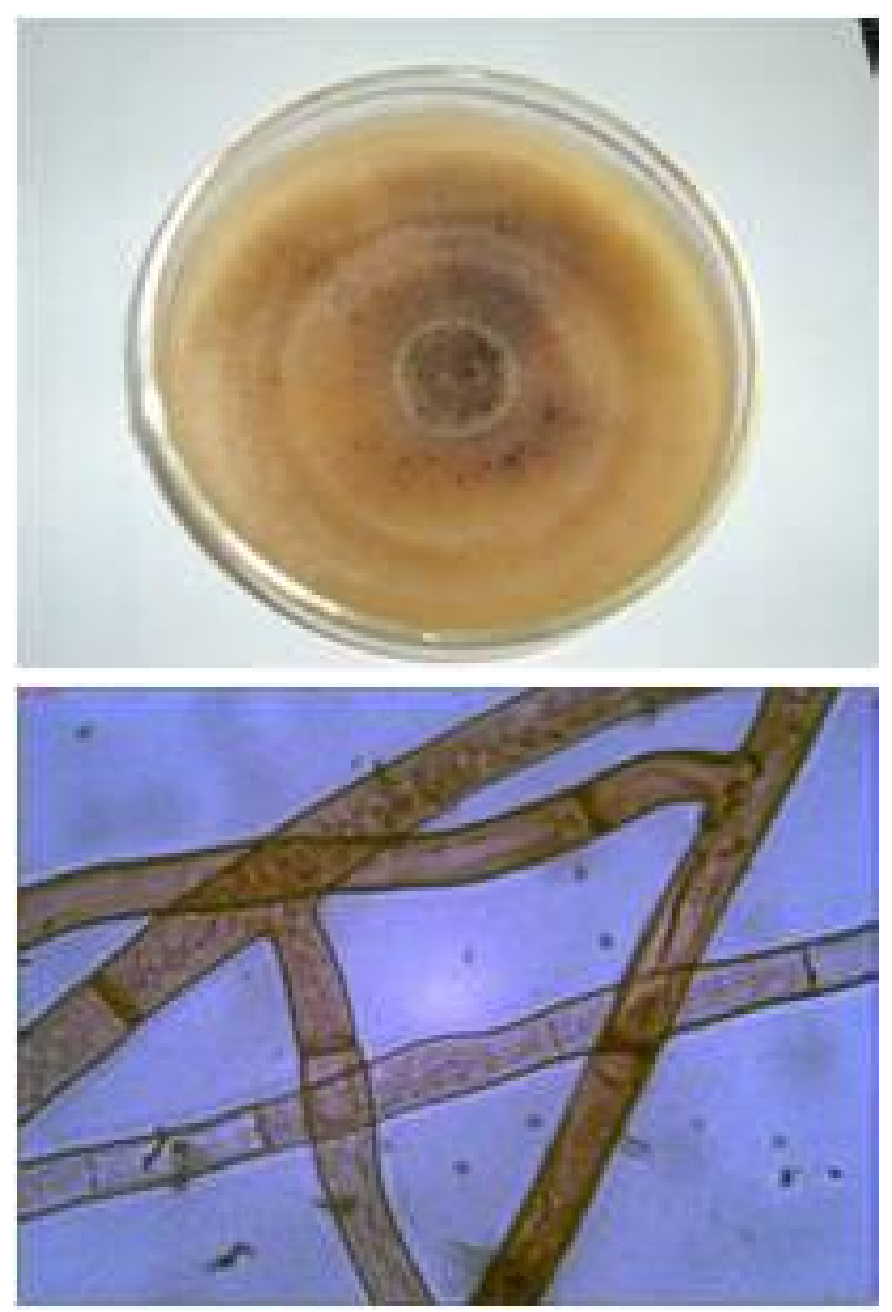

Figura 2. Colônia de $R$. solani AG4-HGI em meio BDA e hifas do patógeno. 